\title{
A IMPORTÂNCIA DO ASSISTENTE SOCIAL NAS COMISSÕES INTRA-HOSPITALARES DE DOAÇÃO DE ÓRGÃOS E TECIDOS PARA TRANSPLANTES
}

\author{
The importance of Social Workers Committees into the intra-hospital organ and tissue donation for \\ transplantation.
}

Sílvia Franco Dórea Bandeira, Sandra Maria Melo Behrens

\begin{abstract}
RESUMO
As mudanças no sistema de saúde promoveram transformações nas diversas áreas e profissões de saúde. No âmbito das CIHDOTT, o Assistente Social encontra mais um espaço profissional para desenvolver sua atuação, na perspectiva da garantia dos direitos sociais numa práxis atuante e inovadora. O tema sobre o qual versa este artigo objetiva descrever a importância atual do Assistente Social junto ao Sistema Nacional de Transplantes. A metodologia utilizada foi a pesquisa bibliográfica e descritiva acerca do trabalho vivenciado pelas autoras na Coordenação do Sistema Estadual de Transplantes no Estado da Bahia. Conclui-se que hoje, esse profissional de saúde atua como mediador junto às famílias, estando mais voltado para o processo de morte/morrer, colocando-se como um dos importantes suportes profissionais no momento da doação/transplante. O Assistente Social conquista mais espaço, renovando-se no âmbito teórico-metodológico e ético-político, inserindo uma nova dimensão ao Serviço Social na área de saúde.
\end{abstract}

Descritores: Serviço Social; Assistência Social; Saúde Pública-Organização e Administração; Serviços de Saúde; Transplante de Órgãos.

Instituição:

Secretaria da Saúde, Serviço Social da Coordenação do Sistema Estadual de Transplante (COSET), Salvador, Bahia, Brasil.

\section{Correspondência:}

\section{Sílvia Franco Dórea Bandeira}

Av. Luís Viana Filho, $4^{\mathrm{a}}$ Avenida, Plataforma 6, lado B, $\mathrm{n}^{\circ} 400,4^{\circ}$ andar, Centro Administrativo da Bahia, Sussuarana, Salvador, Bahia, CEP 41745-000.

Tels: (71) 3115-8316 / 3353-7822 / 9602-8867

E-mail: sfdb80@yahoo.com.br

Recebido em: 23.03.2009

Aceito em: 30.09 .2009

\section{INTRODUÇÃO}

\section{Breve histórico do Serviço Social na área de saúde}

A Revolução Industrial evidenciou a necessidade do reconhecimento dos direitos sociais provenientes das reivindicações populares resultantes dos problemas sociais e econômicos advindos da industrialização.

Bartolomei et al ${ }^{1}$ comentam que após essa tomada de consciência, em conjunto com o fato dos direitos individuais já terem sido garantidos pelo Estado Liberal, surgiram os direitos sociais. Após a segunda Guerra Mundial, em virtude das atrocidades sofridas durante o conflito, iniciou-se um questionamento sobre as condições humanas e a necessidade de garantia efetiva dos direitos humanos. Os Estados foram obrigados a concretizar os direitos sociais, o direito à educação, o direito à alimentação, o direito à moradia e o direito à saúde, entre outros.

Daremos ênfase ao direito à saúde, conceituando-o como o conjunto de normas jurídicas que regulam as atividades sanitárias estatais e definem os meios de que o Estado dispõe para concretizar esse direito, desde a definição dos aspectos organizacionais e 
operacionais do sistema de saúde, o estabelecimento da forma e dos critérios a serem observados na formulação e implementação das políticas de saúde até normas específicas aplicáveis a bens e serviços de interesse à saúde. ${ }^{1}$

A Reforma Sanitária brasileira ocorreu na década de 70, e a partir daí, foi redefinido o conceito de saúde disposto na Constituição de 1988:

A saúde não é um conceito abstrato. Define-se no contexto histórico de determinada sociedade e num dado momento do seu desenvolvimento, devendo ser conquistada pela população em suas lutas cotidianas. Em seu sentido mais abrangente, a saúde é a resultante das condições de alimentação, habitação, educação, renda, meio ambiente, transporte, lazer, liberdade, acesso e posse da terra e acesso a serviços de saúde. É assim, antes de tudo, o resultado de organização social da produção, as quais podem gerar grandes desigualdades nos níveis de vida. ${ }^{2}$

No âmbito da saúde, após a promulgação da Constituição de 1988, grande parte das reivindicações constantes no movimento da Reforma Sanitária foi atendida, sendo o SUS o ápice desse processo. Nortearam a reconceituação da saúde as Leis 8.080/90 e 8.142.

A Lei ${ }^{\circ} 8.080 / 90$, em seu artigo $4^{\circ}$, define o SUS como:

O conjunto de ações e serviços de saúde prestados por órgãos e instituições públicas federais, estaduais e municipais, da Administração direta e indireta e das fundações mantidas pelo Poder Público. $^{3}$

Observa-se assim, que essa lei tem a função principal de dar visibilidade e estrutura ao Sistema Único de Saúde (SUS), criado com o objetivo de prestar serviço de saúde a quem necessite.

A saúde integra diversos profissionais como: médicos, enfermeiros, radiologistas, técnicos de enfermagem, fisioterapeutas, assistentes sociais, cada um trabalhando em sua área, em prol do cuidado e da cura do paciente.

A função do Assistente Social na área de saúde está delineada no artigo $3^{\circ}$ da Lei 8080 , que insere esse profissional nas políticas sociais a nível intersetorial e interdisciplinar na questão da saúde, conforme abaixo descrito:

Artigo $3^{\circ}$ : A saúde tem como fatores determinantes e condicionantes, entre outros, a alimentação, a moradia, o saneamento básico, o meio ambiente, o trabalho, a renda, a educação, o transporte, o lazer e o acesso aos bens e serviços essenciais; os níveis de saúde da população expressam a organização social e econômica do País.

Parágrafo único. Dizem respeito também à saúde as ações que, por força do disposto no artigo anterior, se destinam a garantir às pessoas e à coletividade condições de bem-estar físico, mental e social. ${ }^{3}$

Assim, entende-se que o papel do Assistente Social é de grande relevância na concretização do atual conceito de saúde, que destaca no art. $3^{\circ}$ da lei citada acima os elementos determinantes do processo saúde-doença.

Consoante ao que reza a Resolução n. ${ }^{\circ}$ 218, de 06 de março de 1997 do Conselho Nacional de Saúde/Ministério da Saúde, o Serviço Social passa a ser uma profissão reconhecida como inerente à área de saúde. Também o Conselho Federal de Serviço Social (CEFESS), através da Resolução no 338/1999, confirma o assistente social como profissional de saúde.

O Assistente Social passou então a redefinir o seu papel profissional, assumindo novas funções: participando do processo de gestão da saúde, atuando nos conselhos de saúde, na formulação, planejamento, execução, monitoramento e avaliação das políticas públicas.

O contexto histórico do Serviço Social norteia sua importância no âmbito da saúde, reafirmando os pressupostos ético-políticos e o compromisso da profissão em defesa dos direitos dos pacientes.

A Reforma Sanitária desencadeou profundas mudanças na saúde. Uma delas foi na área de Assistência Social, que passou a atuar como agente de interação entre o SUS e as políticas sociais, bem como interferindo positivamente nas contradições desse sistema de saúde. Além disso, estreitou mais seu foco social, desenvolvendo mais atividades de natureza educativa e de incentivo à participação popular/controle social junto à comunidade.

As mudanças configuradas através do SUS tiveram avanços relevantes na ampliação da atenção básica, programas de saúde da família e agentes comunitários que alteraram a realidade das camadas populares, tendo o assistente social como um dos articuladores desse processo.

Essa visão da atuação do assistente social coloca-o na dimensão ideopolítica articulada com a perspectiva da garantia dos direitos sociais.

O Serviço Social vem historicamente alcançando destaque como uma profissão capaz de analisar criticamente a realidade em que se delineia, buscando avançar na proposição de uma práxis mais atuante e inovadora, sempre com entusiasmo no vivenciar experiências inusitadas, questionando preconceitos e criando novas diretrizes que norteiam a profissão.

\section{O Papel do Assistente Social nas Comissões Intra- Hospitalares de Doação de Órgãos e Tecidos para Transplantes}

O Assistente Social que trabalha nas Comissões de Transplante tem um papel fundamental na composição da equipe multidisciplinar que lidará diretamente com a família do provável doador. O Assistente Social e o Psicólogo são os profissionais mais indicados (grifo nosso) para manter o contato inicial com a família do paciente que se encontra em morte encefálica.

Faz-se mister enfatizar que o atendimento humanitário, acolhedor, ágil e eficaz desse paciente desde o momento da internação (grifo nosso), proporcionará maior probabilidade da família aceitar a doação dos órgãos de seu ente querido. Os esforços empreendidos pela equipe médica para mantê-lo vivo serão uma atenuante que tende a fazer diferença no momento do contato com a família.

O Assistente Social deverá ter equilíbrio e serenidade emocional para lidar com o tema morte e com as reações adversas das famílias no momento inicial da entrevista. Cabe ao Assistente Social perceber qual o momento adequado para tratar do assunto doação. O ouvir é de extrema importância nos contatos iniciais, principalmente se o profissional ainda não conhece a família do provável doador. O acolhimento e o suporte emocional do profissional junto à família são imprescindíveis para criar um elo de confiança. A relevância do processo de acolhimento traduz-se através do conceito de Merhy. ${ }^{4}$

O encontro entre sujeitos se dá num espaço intercesso no qual se produz uma relação de escuta e responsabilização, a partir do que se constituem vínculos e compromissos que norteiam os projetos de intervenção. Esse espaço permite que o trabalhador use de sua principal tecnologia, o saber, tratando o usuário como sujeito portador e criador de direitos. O objetivo da intervenção seria o controle do sofrimento [...]. ${ }^{4}$ 
No dia-a-dia do trabalho do profissional de saúde, a regra geral é dar muito de si mesmo em termos profissionais e humanísticos em qualquer área do hospital. O lidar constante com paradigmas como vida e morte, sucesso e fracasso (quando não se consegue reverter o processo da morte), o estar sempre a postos e com agilidade é uma obrigação, conforme evidenciam Codo; Jacques. ${ }^{5}$

Sobre o profissional de saúde e o seu espaço de trabalho, Lima; Carvalho, ${ }^{6}$ afirmam que:

O ambiente hospitalar gera estresse de várias naturezas e em vários níveis por lidar com o sofrimento e a dor e muitas vezes ter de presenciar a morte e o morrer, os profissionais de saúde podem ser levados a um crescente estresse decorrente de seu trabalho. ${ }^{6}$

A perda de alguém tende a provocar mudanças. A morte normalmente é um processo de difícil aceitação, mesmo após seu acontecimento. A família depara-se com comportamentos e sentimentos até então desconhecidos. Alguém que se ama morre, parte para sempre e deixa um vazio doloroso e indescritível para muitas famílias.

A questão da morte, enquanto um dos eventos presente na atuação do profissional na área da saúde e o modo como os profissionais são preparados para lidar com temas de tal complexidade devem ser questões a serem levantadas nas Faculdades de Serviço Social e trabalhadas durante a formação profissional. Será que os profissionais da área de saúde estão capacitados para entender e atuar quando se vêem diante de uma situação que envolva a morte? Como esses profissionais encaram a morte e a negação da família?

O Assistente Social deveria aprofundar-se nas questões que dizem respeito à morte. No entanto, no Curso de Serviço Social, como também em outros cursos da área de saúde, a morte ainda não é vista como prioridade no preparo do profissional. Constitui um tema considerado dispensável. Não se ensina como abordar a família, como comunicar o óbito. $\mathrm{O}$ assistente social e a maioria dos profissionais de saúde aprendem na prática cotidiana. Em geral, os profissionais são capacitados para lidar com a vida, e não com a morte.

Seminários e grupos de discussão podem colaborar na mudança desse quadro. A formação, que é vista como inadequada pelos profissionais, modificará a atitude do profissional frente a essa situação e poderá dar-lhe segurança e habilidade para dar suporte emocional mais adequado àqueles que se separaram de seu ente querido.

O conviver com a morte diariamente nos hospitais induz os profissionais da área de saúde a encararem com certa naturalidade, frieza ou indiferença o processo da morte. Esse comportamento se traduz em uma tentativa de se resguardar e não vivenciar sentimentos que possam desestabilizá-lo. Mas o assistente social, em particular, deve atuar de forma mais adequada à situação para que seu contato com a família não seja prejudicado. Os familiares não desejam ser acolhidos por profissionais frios e indiferentes, que se deixaram levar pelas rotinas da Instituição à qual pertencem.

Com a família, o profissional deverá inicialmente acolher devido à dor da perda. Posteriormente, poderá proporcionar aos familiares uma auto-avaliação, para que os mesmos possam rever todo o processo até o momento do óbito. Deverá também proporcionar oportunidade para que a família reveja seus conceitos acerca da morte e doação de órgãos, esclarecendo suas dúvidas, e informando sobre a realidade das pessoas que aguardam por esse ato de solidariedade.

Não cabe aos componentes das equipes das Comissões IntraHospitalares de Doação de Órgãos e Tecidos para Transplante, principalmente ao Assistente Social, notificar os familiares da morte encefálica ou óbito do seu paciente. Porém, o mesmo deverá compor a equipe do hospital no momento do diagnóstico e se fazer conhecer pela família (grifo nosso). O primeiro contato da equipe só é mantido após a confirmação e comprovação da morte encefálica e a certeza das condições apropriadas para que ocorra a doação.

O correto posicionamento do Assistente Social poderá garantir o êxito da captação. Frases persuasivas, imposição, impaciência, questionamentos acerca da opção da família podem interferir negativamente no processo de doação. A família deve ser respeitada sobre sua decisão, mesmo que esta seja contrária à doação. $\mathrm{O}$ profissional deve usar todos os argumentos éticos que possam subsidiar a tomada de decisão pela família, atentando para o momento adequado de encerrar a entrevista e saber respeitar de forma serena a decisão final dos familiares.

O Assistente Social também deve ser capaz de perceber se a decisão foi consenso familiar ou se existe algum membro contrário que poderá prejudicar o processo de doação; saber intervir no momento oportuno para evitar constrangimento e situações delicadas e intermediar na decisão familiar, podendo suspender o processo de doação, caso não haja consenso.

Insta ressaltar que é crucial ter sensibilidade para lidar com temas como “morte e religião”. A crença de cada um deve ser respeitada, mesmo que seja contrária à doação de órgãos e tecidos. Trata-se de tema muito polêmico, que deve ser trabalhado preventivamente em escolas, universidades, centros comunitários, unidades de saúde e entidades religiosas. Enquanto esse processo não for prioritário, o trabalho desse profissional de saúde será de eterna luta. Semear o terreno árido e aguardar a colheita.

Destarte, fatores culturais também interferem nesse momento de comunicação. Respeitar as percepções e limitações dos familiares e tentar junto aos mesmos refletir a importância do ato são papéis do profissional comprometido com a causa. A maneira de pensar e sentir de cada um e sua realidade de vida estão ligados à decisão de doar ou não.

A abordagem familiar deve ser realizada em local tranqüilo no ambiente hospitalar, preferencialmente em sala especifica para atendimento, conforme dispõe a RDC CFESS no 493/2006. O assistente social deverá ter o cuidado de não ser interrompido. A equipe também deverá estar ciente da importância desse momento de abordagem e intervir, caso seja necessário. É importante que não se quebre o elo de envolvimento entre o assistente social e a família durante a entrevista.

As principais causas de recusa da família devem-se ao fato do paciente nunca ter expressado sua intenção de ser doador, a crenças religiosas contrárias ao assunto e ao atendimento inicial na Unidade Hospitalar. Quando os familiares deparam-se com a morte encefálica ou óbito de um parente e são abordados para pensarem na possibilidade de doação, muitos reavaliam atitudes, conceitos, crenças, posturas e decidem pelo que lhes parece mais coerente com seu modo de viver.

O tema morte encefálica ainda é desconhecido e mal entendido por muitas famílias, que questionam como o coração ainda bate e seu paciente está morto. A esperança é a última que morre, é o que muitos acreditam. É uma forma de não assumirem essa responsabilidade. Debates sobre o tema devem ser inseridos para esclarecimento nos Órgãos Públicos e demais espaços sociais de comunicação e educação em saúde. 


\section{Morte encefálica}

Em virtude da doação de órgãos para fins de transplantes advir de óbito por morte encefálica, é necessário definir tal quadro clínico.

Sobre esse tipo de morte, Moura ${ }^{7}$ ressalta que:

Constatada e documentada a morte encefálica, deverá o Diretor da instituição hospitalar ou a quem for delegado comunicar tal fato aos responsáveis legais do paciente, se houver, e à Central de Notificação, Captação e Distribuição de Órgãos a que estiver vinculada a unidade hospitalar onde o mesmo se encontrava internado.?

A Resolução n ${ }^{\circ}$ 1.480, de 08 de agosto de 1997, do Conselho Federal de Medicina, em seu artigo $9^{\circ}$, reza o seguinte sobre morte encefálica:

A propósito, a Morte Encefálica ou morte do encéfalo (cérebro e tronco cerebral) equivale à morte clínica estabelecida pelos critérios neurológicos. A Morte Encefálica é estabelecida pela perda definitiva e irreversível das funções do encéfalo, por uma causa conhecida (estrutural ou metabólica), comprovada e capaz de provocar o quadro clínico. ${ }^{8}$

Nesse aspecto, algumas dificuldades são verificadas, posto que a CNCDO (Central de Notificação, Captação e Distribuição de Órgãos) não tem recebido as notificações de morte encefálica necessárias para desencadear o procedimento de doação de órgãos. Essas dificuldades perpassam, sobretudo, pela falta de cultura em doação/transplantes no nosso Estado, ausência de conscientização dos profissionais de saúde, além de negativa familiar.

No tocante ao processo doação / transplante, insta ressaltar a legislação que ampara a criação das Comissões Intra-Hospitalares de Doação de Órgãos e Tecidos para Transplantes (CIHDOTT) através da Portaria $n^{\circ} 1.752 / 2005$.

Determina a constituição de Comissão Intra-Hospitalar de Doação de Órgãos e Tecidos para Transplante em todos os hospitais públicos, privados e filantrópicos com mais de 80 leitos. $^{9}$

As Comissões Intra-Hospitalares para Doação de Órgãos e Tecidos para Transplantes (CIHDOTTs) estão sendo constituídas, treinadas e já começam a produzir frutos, conscientizando técnicos de saúde e população que pouco conhecia o tema.

As CIHDOTT apresentam-se em diversos estágios, estando algumas mais estruturadas e outras não, com dificuldades de toda ordem. Destacam-se recursos materiais e humanos não disponibilizados - muitas vezes por quantitativo insuficiente de servidores na assistência, que não podem ser disponibilizados para outras atividades pela Direção da Unidade, para não desfalcar o atendimento - e falta de espaço físico para o devido acolhimento às famílias.

A estruturação das Comissões com dedicação exclusiva faz-se imprescindível, para que as famílias em situação de sofrimento possam ter uma boa acolhida no momento da perda do seu ente querido, receber orientações sobre o procedimento e, quiçá, decidirse pela doação de órgãos e tecidos.

Ainda sobre as CIHDOTT, a Portaria $n^{\circ} 1.262$ de 16 de junho de 2006 determina sobre a Comissão, sua estrutura, constituição, obrigatoriedades e capacitação dos seus membros.

Aprova o Regulamento Técnico para estabelecer as atribuições, deveres e indicadores de eficiência e do potencial de doação de órgãos e tecidos relativos às Comissões Intra-hospitalares de Doação de Órgãos e Tecidos para Transplantes (CIHDOTT).
Art. 1: A Comissão Intra-Hospitalar de Doação de Órgãos e Tecidos para Transplante deve ser composta por no mínimo três membros de nível superior, integrantes do corpo funcional do estabelecimento de saúde, dentre os quais 1 (um) médico ou enfermeiro, designado como Coordenador Intra-Hospitalar de Doação de Órgãos e Tecidos para Transplante.

$\S 1^{\circ} \quad$ A Comissão de que trata este artigo deverá ser instituída por ato formal da direção de cada hospital e estar diretamente vinculada à diretoria médica do estabelecimento.

$\S 2^{\circ}$ Os membros da Comissão não devem ser integrantes de equipe de transplante e/ou remoção de órgãos ou tecidos ou integrar equipe de diagnóstico de morte encefálica.

$\S 3^{\circ}$ O coordenador deverá ter certificação de Curso de Formação de Coordenadores Intra Hospitalares de Doação de Órgãos e Tecidos para Transplante, ministrado pelo Sistema Nacional de Transplante (SNT) ou pelas Centrais de Notificação, Captação e Distribuição de Órgãos dos Estados ou Distrito Federal, validado pelo $\mathrm{SNT}^{10}$

As atribuições da CIHDOTT estão normatizadas na Portaria ${ }^{\circ}$ 1752 de 23 de setembro de 2005, artigo segundo e seus incisos, que tratam de formalizar os procedimentos desta comissão.

Art. $2^{\circ}$ Cabe à Comissão Intra-Hospitalar de Doação de Órgãos e Tecidos para Transplante:

I. articular-se com a Central de Notificação, Captação e Distribuição de Órgãos do Estado ou Distrito Federal (CNCDO), notificando as situações de possíveis doações de órgãos e tecidos;

II. identificar os recursos diagnósticos disponíveis na instituição, necessários para a avaliação do possível doador de órgãos e/ ou tecidos;

III. articular-se com os profissionais de saúde encarregados do diagnóstico de morte encefálica e manutenção de potenciais doadores, objetivando a otimização do processo de doação e captação de órgãos e tecidos;

IV. organizar, no âmbito da instituição, rotinas e protocolos que possibilitem o processo de doação de órgãos e tecidos;

V. garantir uma adequada entrevista familiar para solicitação da doação;

VI. promover programa de educação continuada de todos os profissionais do estabelecimento para compreensão do processo de doação de órgãos e tecidos;

VII. disponibilizar os insumos necessários para a captação efetiva de órgãos e tecidos no hospital. ${ }^{10}$

Vale ressaltar que a primeira CIHDOTT de que se tem notícia surgiu no Hospital Geral do Estado nos anos 90 e foi presidida pela Assistente Social Mara Rebouças, o que denota a importância do papel do Serviço Social na CIHDOTT, mesmo na qualidade de Presidente, o que vai ao encontro da atual legislação, conforme dispõe a portaria supra citada, determinando que as CIHDOTT sejam presididas por profissional médico ou de enfermagem.

A despeito da legislação atual que regulamenta a matéria, entendemos que não há que se falar em Presidência de CIHDOTT com exclusividade para os profissionais retro mencionados (médico 
ou enfermeiro), posto que, a nosso ver, não entendemos o porquê de tal limitação. Tanto assistentes sociais como psicólogos ou outros profissionais da área de saúde estão aptos a exercer esse ministério, sem que o trabalho da CIHDOTT sofra solução de continuidade. Este é o nosso posicionamento. A formação da CIHDOTT do HGE com uma assistente social presidindo à época já denota na práxis profissional o êxito da experiência.

Outro fator preponderante é a capacitação contínua desses profissionais que atuam em momento tão ímpar e decisivo para o processo doação / transplante. Tanto o Coordenador como os membros devem ser reciclados periodicamente e estar sempre motivados para desenvolver suas atribuições, principalmente no que concerne ao acolhimento e entrevista familiar.

\section{CONCLUSÃO}

Através das experiências vivenciadas pelos assistentes sociais que trabalham em hospitais, especificamente nas CIHDOTT, podemos afirmar que algumas inquietações e desafios movem esse profissional, que vem conquistando espaço, renovando-se no âmbito teórico-metodológico e ético-político, adequando sua prática profissional ao foco imediato de sua intervenção, que é o tema em pauta neste artigo: a morte, a família e a doação de órgãos.

O que foi observado através de nossa vivência como assistentes sociais da Coordenação do Sistema Estadual de Transplantes e que destacamos é a necessidade de profissionais qualificados para atuar nessa área e produzir material que respalde a intervenção profissional, reforçando a abordagem educativa e reflexiva sobre o tema.

Por ser um profissional que está inserido em vários campos de atuação e que historicamente tem papel efetivo na concretização de políticas sociais, o Assistente Social que atua nas CIHDOTT começa a vestir uma roupagem capaz de colocá-lo como facilitador nas relações com a família no âmbito da saúde. Além disso, em virtude das exigências do seu foco de trabalho, vem buscando capacitar-se, procurando incluir em sua formação a especialização em família e em lidar com a morte.

O trabalho desenvolvido na Central de Transplantes só terá sucesso com a parceria da equipe multidisciplinar. O aumento das captações não depende unicamente da atuação do assistente social, pois a aceitação da morte e a doação de órgãos são aspectos que sofrem interferências culturais e religiosas, e a mudança de percepção e comportamentos ocorre lentamente.

Importa repensar na possibilidade do Assistente Social também assumir a Coordenação dessas Comissões. O Assistente Social é profissional capacitado para desenvolver atividades de gerenciamento, competência em lidar com a morte e dinâmica familiar, além de ser um articulador junto a outros profissionais que partilhem dos princípios da CIHDOTT. Para o Serviço Social, o desafio é desenvolver uma gestão social, sem, no entanto, esquecer os elementos da eficácia organizacional.

Outro ponto a destacar é que historicamente, o profissional de Serviço Social tem tido pouca atuação na Gestão do sistema de saúde ou participado do processo decisório da Instituição Hospitalar em que trabalha, subordinando-se às decisões hierárquicas que, muitas vezes, não são focadas na qualidade da prestação de serviços à população. Esse aspecto deve ser repensado e modificado, visando maior êxito do programa de transplantes.

Desejamos ter alcançado nosso intuito de sensibilização dos técnicos de saúde, e, com isso, ampliar o quantitativo de profissionais para esse novo campo de trabalho que se delineia e vem tomando contornos mais nítidos, firmando-se como uma nova terapêutica, quando não é mais possível qualquer outra forma de tratamento que não seja o transplante. É o aprender a trabalhar com a morte, e não mais com a vida.

\section{ABSTRACT}

Changes in the health system have promoted changes in several areas and to health professions. As to the CIHDOTT, Social Workers have another professional field of action to develop their skills, changing from a merely ideological aspect towards a mean to assure some social rights towards a more active and innovative practice. The subject of this article aims to describe the importance of the present Social Worker as to the National Transplantation System. The methodology used was the literature review and to perform a description on the authors' job experience in the Transplant Coordination System in the State of Bahia. It was concluded that nowadays, the health professional actuates as a mediator to families, more focused on the death / dying process serving as a supporter to the donation / transplant process. Social Workers get more room, renewing themselves in the theoretical and methodological structure and policies, inserting a new step to the social services in the health care.

Keywords: Social Work; Social Assistance; Public Health - organization and administration; Organ Transplantation

\section{REFERÊNCIAS}

1. Bartolomei CEF, Carvalho MS, Delduque MD. A saúde é um direito. Saúde Debate 2003 Set./Dez; 27(65):184-91.

2. Anais da $8^{\text {a }}$ Conferência Nacional de Saúde. 1986 mar. 17-21 ; Brasília: Ministério da Saúde; 1987.

3. Brasil. Lei $n^{\circ} 8.080$, de 19 de setembro de 1990. Dispõe sobre as condições para a promoção, proteção e recuperação da saúde, a organização e o funcionamento dos serviços correspondentes e dá outras providências. Brasília: Presidência da República; 1990.

4. Merhy EE. O SUS e um dos seus dilemas: mudar a gestão e a lógica do processo de trabalho em saúde: um ensaio sobre a micropolítica do trabalho vivo. In: Fleury S. Saúde e democracia: a luta do Cebes. São Paulo: Lemos Editorial; 1997. p. 125-41.

5. Codo W, Jacques MG. Saúde mental e trabalho. Petropólis: Vozes; 2002. p.13. 